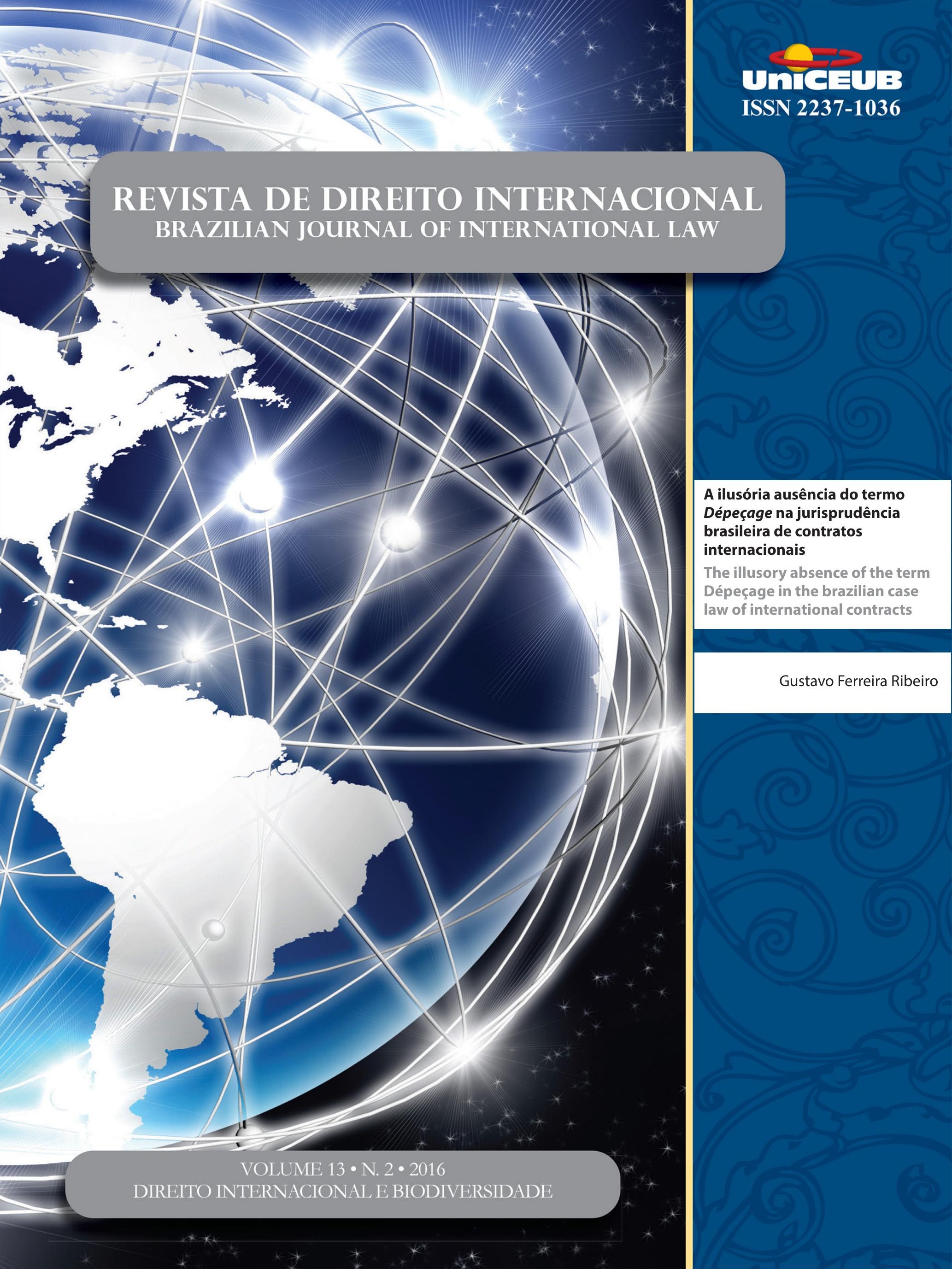




\section{Sumário}

CRÔNICAS DE DIREITO INTERNACIONAL PRIVADO 3 Gustavo Ferreira Ribeiro, Inez Lopes Matos Carneiro de Farias, Nadia de Araujo e Marcelo De Nardi

EDITORIAL 22

Márcia Dieguez Leuzinger e Solange Teles da Silva

IMPROVING THE EFFECTIVENESS OF LEGAL ARRANGEMENTS TO PROTECT BIODIVERSITY: AUSTRALIA AND BRAZIL .25

Paul Martin, Márcia Dieguez Leuzinger e Solange Teles da Silva

O RECONHECIMENTO DA DIGNIDADE DOS ELEMENTOS DA BIODIVERSIDADE COM BASE NO DIÁLOGO ENTRE O DIREITO INTERNACIONAL E O ORDENAMENTO JURÍDICO BRASILEIRO

Augusto César Leite de Resende

O REGIME INTERNACIONAL DO CLIMA E A PROTEÇÃO AOS “REFUgIADOS CLIMÁTICOS”: QUAIS DESAFIOS DA COP 21?

Ana Carolina Barbosa Pereira Matos e Tarin Cristino Frota Mont'Alverne

A anÁlise do MECANismo REdD+ COM Vistas À MitigaÇÃo dos EFEITOS DAS MUdANÇAS CLIMÁTICAS E À PROTEÇÃO DA DIVERSIDADE BIOLÓGICA FLORESTAL

Diogo Andreola Serraglio e Heline Sivini Ferreira

ECOLABELS DE EFICIÊNCIA ENERGÉtiCA E SUA CONSISTÊNCIA COM A DISCIPLINA DOS PPM's E PROVISÕES dOs Acordos GATT E TBT.

Cristiane Derani e Arthur Rodrigues Dalmarco

ANÁLISIS DEL ORDENAMIENTO JURÍDICO INTERNACIONAL SOBRE PROTECCIÓN DE LOS RECURSOS GENÉTICOS: DESAFIOS Y PERSPECTIVAS EN URUGUAY A PARTIR DE LA IMPLEMENTACIÓN DEL PROTOCOLO DE NAgOYA 115

Alina Celi 
LE RÉGIME INTERNATIONAL DE L'ACCÈS AUX RESSOURCES GÉNÉTIQUES AU PRISME DE L'ENTRÉE

en VIgUeUr du Protocole de NAgoya .............................................................. 131

Rodolpho Zahluth Bastos, Otávio Canto, Karine Galy e Isabelle Vestris

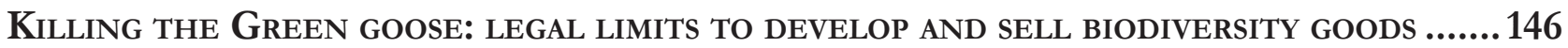
José Augusto Fontoura Costa e Liziane Paixão Silva Oliveira

VÍNCULO SUBSTANCIAL E AS BANDEIRAS DE CONVENIÊNCIA: CONSEQUÊNCIAS AMBIENTAIS DECORRENTES DOS NAVIOS COM REGISTROS ABERTOS ....................................................... 160

Marcos Edmar Ramos Alvares da Silva e André de Paiva Toledo

ANÁLISE DE CONTRATOS PÚblicos SOCIOAMBIENTAIS NO CENÁRIO PORTUGUÊS DE CRISE ECONÔ-

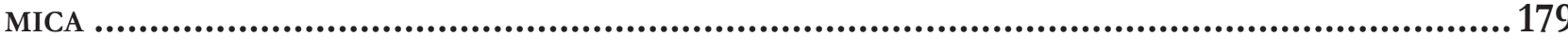

Alice Rocha da Silva e Matheus Passos Silva

A ORganizaÇão do TRATAdo DE COOPERAÇão AMAZÔNICA: UMA ANÁLISE CRÍTICA dAS RAZÕES POR TRÁS DA SUA CRIAÇÃO E EVOLUÇÃO

Paulo Henrique Faria Nunes

O uso de EXPERTS EM Controvérsias ambientais Perante a CorTe InTERnacional de JusTIÇA ........................................................................................................245

Lucas Carlos Lima

Os VIESES dA BIODIVERSIDAdE APRESENTAdos PELO CASO do PARQUE EÓlico DE BALd HiLls ......261 Natália Zampieri e Mariana Cabral

Mining CBD 275

Claire Lajaunie e Pierre Mazzega

Biotecnologia moderna, direito e o pensamento Abissal

Reichardt, F.V., Garavello, M. E. P. E., Molina, S.M.G. e Ballester, M. V. R.

Community Core Values como parâmetro de efetivação dos Princípios da Precaução e da Participação Popular em instrumentos de controle de projeto atividade de alta COMPLEXIDADE AMBIENTAL................................................................................... 314

Michelle Lucas Cardoso Balbino 
Discussões BIOTECNOLÓgICAS QUANTO AOS ORGANISMOS GENETICAMENTE MODIFICADOS NO ÂMBito da OMC: do contencioso ao acordo de vontades entre Argentina e União EuroPEIA

Gustavo Paschoal Oliveira

O Trans-Pacific Partnership Agreement e seus potenciais impactos para a regulação

DA BIODIVERSIDADE NO ÂMBITO TRANSNACIONAL..........................................................375

Mariana Yante Barrêto Pereira

AS ÁREAS PROTEGIDAS TRANSFRONTEIRIÇAS: REFLEXÕES CRÍTICAS ACERCA DE UM USO GEOPOLÍTICO DO DIREITO DA BIODIVERSIDADE.

Rabah Belaidi

O Que o caso Estados Unidos vs. Texas nos dirá sobre o direito de IMigração nos EsTADOS UNIDOS? 409

Danielle Anne Pamplona

Clóvis Beviláqua e a justiça internacional: entre o sim E o Não a Rui Barbosa.... .422 Paulo Emílio Vauthier Borges de Macedo

Possibilidade de delegação de atribuição para a Celebração de Tratados pela RepúbliCa Federativa do Brasil: análise do artigo 84, VIII c/c Parágrafo único da ConstituiÇão FEDERAL

Luciano Monti Favaro e Héctor Valverde Santana

Dignity, ubuntu, HUMANiTY AND AUTONOMOUS WEAPON SYSTEMS (AWS) DEBATE: AN AfRiCAN PERSPECTIVE 460

Thompson Chengeta

DiREITO INTERNACIONAL PRIVADO E O DIREITO TRANSNACIONAL: ENTRE A UNIFICAÇÃO E A ANARQUIA .503

André De Carvalho Ramos

A ilusória ausênCia do termo DépeÇage na JURisprudênCia brasileira de contratos INTERNACIONAIS

Gustavo Ferreira Ribeiro 
O EFEITO DIRETO DAS DIRETIVAS E OS DIREITOS FUNDAMENTAIS........................................535 Lucas Fonseca e Melo e José Levi Mello do Amaral Júnior

DA APLICABILIDADE DO BULK FACTORING AOS GRUPOS DE SOCIEDADES 565 Daniel Amin Ferraz e Leonardo Arêba Pinto

A Questão hermenêutica no direito das GENTES ................................................580 Inocêncio Mártires Coelho 


\title{
A ilusória ausência do termo Dépeçage na jurisprudência brasileira de contratos internacionais
}

\author{
The illusory absence of the term Dépeçage \\ in the brazilian case law of international \\ contracts
}

Gustavo Ferreira Ribeiro**

\section{Resumo}

O termo dépeçage, scission, morcellement, fracionamento, despedaçamento, desmembramento, entre outros, é mencionado, sem grande uniformidade, na doutrina de contratos internacionais. Refere-se à possibilidade de, em diferentes graus e amplitude, aplicarem-se normas de mais de um sistema legal ao contrato conectado a mais de uma jurisdição. Ao se pesquisar a jurisprudência, contudo, não se encontrou o uso do termo dépeçage nos tribunais brasileiros selecionados em um período recente (2006-2015). Diante do paradoxo, este artigo buscou revisitar a doutrina comparada (Francesa, Alemã, Norte-Americana) e pátria acerca do tema. Depreende-se significativa variação na definição do dépeçage. Sugiro, assim, que a ausência de resultados nas Cortes brasileiras é ilusória. Dependendo da definição, pode-se afirmar que o dépeçage é, de fato, parte do sistema brasileiro de conflito de leis em direito contratual, sem que seja expressamente mencionado. Corrobora-se assim uma maior utilidade da ideia de espectros de dépeçage, proposta por Friedrich Juenger, para análise do tópico.

Palavras-Chave: Contratos Internacionais. Doutrina do Dépeçage. Jurisprudência brasileira.

\section{Abstract}

The term dépeçage, scission, morcellement, and splitting, among others, is mentioned, without more uniformity, in the international contracts doctrine. It refers to the possibility of, in different levels and amplitude, apply norms of more than one legal system to the contract connected to more than one jurisdiction. While searching legal cases, however, one cannot find the term dépeçage in selected Brazilian case law in a recent period (2006-2015). Confronted with this paradox, this paper revisited comparative (French, German and North-American) and domestic doctrine. It found significant variation in the definition of dépeçage. I suggest, thus, that the absence of results in the Brazilian case law is illusory. Depending on the definition, one can say that dépeçage is, in fact, part of the Brazilian system of conflicts of law concerning contracts, regardless of express reference. The paper there-

** Professor do Programa de Mestrado e Doutorado em Direito - UniCEUB, Brasília. Email: Gustavo.Ribeiro@uniceub.br. 
fore corroborates that the idea of spectre of dépeçage is of better utility, as proposed by Friedrich Juenger, for the analysis of the topic.

Keywords: International Contracts. Depéçage Doctrine. Brazilian Case Law.

\section{INTRODUÇão}

O termo dépeçage aparece com distintas variações na literatura jurídica. Morcellement, découpage, scission, splitting, slicing, e suas variações no vernáculo - fracionamento, despedaçamento, desmembramento, entre outras -, são mencionadas na doutrina doméstica e comparada abarcando contratos internacionais. Com pouca precisão e uniformidade.

Em versões mais restritas, identifica-se o instituto com a possibilidade de, em um contrato conectado a mais de uma jurisdição, reger-se seu direito substantivo - sua matéria ou o fundo do contrato - por mais de um sistema jurídico. Essa possibilidade decorreria, por exemplo, da autonomia das partes em escolher mais de um direito aplicável ao contrato. Nas versões mais amplas, a mera possibilidade de que a capacidade dos contratantes, forma e substância de um mesmo contrato estarem regidos por sistemas distintos aparece como uma ilustração do instituto. No limite, há autores que indicam que quando a lei processual aplicável ao contrato for uma (tradicionalmente, a lex for $)$ e qualquer outra lei aplicável ao contrato for outra (distinta da lex for ), tem-se um exemplo de dépeçage.

Tomemos o sistema jurídico brasileiro de conflito de leis no espaço como referência. A Lei de Introdução às Normas do Direito Brasileiro (LINDB, Decreto-Lei 4.657/1942), sem maiores divergências, possui pontos de conexão que fazem com que a ideia de uma versão mais ampla do dépeçage possa ser subsumida. Em um contrato multiconectado, a capacidade, como se sabe, é regida pela lei de domicílio dos contratantes (lex domicilis, art. 7 da LINDB). A forma, pela lei do local do ato (lex regit actum), regra praticamente universal. Já a substância, pela lei do local de celebração (lex loci celebrationis, caput do art. 9 da LINDB), em regra, por três motivos. Primeiramente, porque é conhecida a divisão na doutrina brasileira sobre uma interpretação literal do caput do artigo 9 da LINDB e o princípio da autonomia da vontade quanto ao direito aplicável aos contratos. Não há pronunciamento definitivo das cortes brasileiras sobre esse ponto ${ }^{1}$. Em segundo lugar, pois a lex loci celebrationis é hipótese aceita para contratos entre pessoas presentes. Para contratos entre ausentes, como os por via eletrônica, a discussão é deslocada para o $\$ 2$ do art. 9 da LINDB. Por fim, há sempre a possibilidade de que, ainda que a regra de remissão - ou de sobredireito - aponte para o direito estrangeiro, a eficácia daquele direito seja potencialmente restringida; por exemplo, por violação à ordem pública (art. 17 da LINDB).

Já versões mais restritas do dépeçage poderiam ser compreendidas em pelos menos duas hipóteses. Admitindo-se autonomia da vontade vis-à-vis o caput do artigo 9 da LINDB, as partes poderiam fracionar o direito aplicável à substância do contrato em quantas partes lhe convenham. Além disso, recentes desenvolvimentos normativos, como a internalização da Convenção da Nações Unidas sobre Contratos de Compra e Venda Internacional de Mercadorias (CISG, no acrônimo mais conhecido em inglês), apontam para a possibilidade do dépeçage $e^{2}$.

Nesse contexto, ao se buscar a jurisprudência correlata para maiores esclarecimentos, o investigador se frustra. Delimitando dez anos de jurisprudência (20062015) do Superior Tribunal de Justiça (STJ) e de seis Tribunais de Justiça relevantes, a pesquisa apontou para a não utilização do termo dépeçage no direito pátrio. Estaria então o dépeçage ausente de nosso sistema? Chegou mesmo a ser introduzido? Ou se trata apenas da não utilização de um termo específico, mas cuja razão subjacente possa ser extraída das decisões?

1 Como resumo, vejam-se VALLADÃO, Haroldo. Direito Internacional privado: em base histórica e comparativa, positiva e doutrinária, especialmente dos Estados Americanos. 5. ed. Rio de Janeiro: F. Bastos, 1980. p. 366-370; RODAS, Jõao Grandino. Elementos de conexão do direito internacional privado brasileiro relativamente às obrigações contratuais. In: RODAS, João Grandino (Org.). Contratos internacionais. 3. ed. São Paulo: Revista dos Tribunais, 2002. p. 43-61. 2 Para desenvolvimentos recentes, veja-se Decreto n. ${ }^{\circ} 8.327$, de 16 de outubro de 2014 que internalizou a Convenção das Nações Unidas sobre Contratos de Compra e Venda Internacional de Mercadorias (CISG). Segundo o art. 6 da CISG: "As partes podem excluir a aplicação desta Convenção, derrogar qualquer de suas disposições ou modificar-lhes os efeitos, observando-se o disposto no Artigo 12". Sobre se tratar de uma hipótese do dépeçage: SCHLECHTRIEM, Peter; SCHWENZER, Ingeborg. Comentários à Convenção da Nações Unidas sobre contratos de compra e venda internacional de mercadorias: artigo 6. São Paulo: Revista dos Tribunais, 2014. p. 243. PIGNATTA, Francisco Augusto. Comentários à Convenção de Viena de 1980: artigo 6. 2012. p. 3-4. Disponível em: <http://www.cisg-brasil.net/doc/ fpignatta-art6.pdf $>$. 
Diante do paradoxo, este artigo revisitou a doutrina comparada (francesa, alemã, norte-Americana) e nacional. Depreendeu-se duas asserções: (i) há significativa amplitude na definição do instituto; e (ii) existem distintos cortes metodológicos na análise do dépeçage. Sugiro, assim, que a ausência de resultados contendo o termo nas cortes brasileiras é ilusória. Deve ser relativizada. Quer-se dizer que dependendo da amplitude e do corte metodológico, o dépeçage é parte do subsistema brasileiro de conflito de leis no direito contratual.

Para a demonstração do proposto, dividiu-se o artigo, além desta (1) introdução, nas seguintes partes. A seção (2) elucida a metodologia de pesquisa jurisprudencial, com a explicitação dos parâmetros de busca e a justificativa da seleção dos tribunais. A seção (3) analisa a doutrina selecionada. A escolha da doutrina francesa e alemã (3.1) decorre da origem etimológica do termo e da relevância dos estudos de Savigny - no conflito de leis de forma geral. A seção (3.2) recorre à doutrina norte-americana. Buscou-se, assim, ampliação do estudo da doutrina comparada, com base em um modelo não continental. Com base nessas considerações, a seção (3.3) traz, por sua vez, a doutrina nacional, revelando seu diálogo e posicionamento com as demais. Na sequência, a seção (4) agrupa os entendimentos, demarca as distintas concepções e corrobora a utilidade da posição conciliadora de espectros de dépeçage, de Juenger. Por fim, a seção conclusiva (5) arremata como ilusória a ausência do termo dépeçage quanto ao direito dos contratos internacionais, sob a ótica do sistema brasileiro.

\section{Observação empírica: AusênCia do termo DÉPEÇAGE}

A presente seção identifica os parâmetros e razões da delimitação da pesquisa jurisprudencial orientada para a busca do dépeçage. Entende-se que o devido detalhamento permite a reprodução da pesquisa e de seus resultados.

Poucos autores no Brasil atentaram, até o momento, a essa observação de uma forma minudenciada. Como exceção, Araujo menciona vários casos em que os tribunais brasileiros cuidaram do tema e, especificamente, um caso de 1986 no qual o extinto Tribunal de Alçada do Rio de Janeiro fracionou um contrato por meio de duas leis regentes aplicáveis à mesma situação. Quanto à substância do contrato e para fatos ocorridos no estrangeiro, aplicou-se a lei estrangeira. No mesmo contrato, para questões relativas a sua execução, a lei do local em que foi realizado (lei brasileira) ${ }^{3}$.

Com base nesses casos, é possível afirmar que as cortes brasileiras se valem do dépeçage em direito contratual?

Como ponto de partida na pesquisa, utilizou-se o termo, com variações, e a limitação temporal de dez anos (2006-2015) nos mecanismos de buscas de determinados sítios eletrônicos de tribunais. Não se fez qualquer limitação, em um primeiro momento, ao tema contratual como operador conjuntivo para a pesquisa, embora seja esse o eixo temático do artigo.

Optou-se pelos mecanismos do Superior Tribunal de Justiça (STJ), dos cinco maiores Tribunais de Justiça das unidades da Federação (SP, RJ, MG, RS e PR), por porte, conforme dados do Conselho de Justiça Federal (2015). Além disso, pesquisou-se a jurisprudência do Tribunal de Justiça do Distrito Federal e Territórios (TJDFT). ${ }^{4}$ A escolha não é aleatória. Primeiramente, tratando-se de tema infraconstitucional, deu-se prioridade na pesquisa pela jurisprudência do STJ, por seu papel uniformizador em matéria dessa natureza. Além disso, a opção pelos cinco maiores Tribunais de Justiça reflete, por óbvio, a expectativa de se cobrir uma extensa quantidade de casos. Finalmente, a pesquisa no TJDFT se justifica pela competência das cortes distritais em diversas situações.

Como ponto comum da pesquisa, excluíram-se decisões monocráticas e se indicou que o intervalo temporal fornecido se referia a data de publicação das decisões, quando existente esta opção. ${ }^{5}$

3 ARAUJO, Nadia de. Contratos internacionais e a jurisprudência brasileira: lei aplicável, ordem pública e cláusula de eleição de foro. In: RODAS, João Grandino (Org.). Contratos Internacionais. 3. ed. São Paulo: Revista dos Tribunais, 2002. p. 208.

4 CONSELHO NACIONAL DE JUSTIÇA. Justiça em números 2015: ano-base 2014. Brasília: CNJ, 2015. p. 61.

5 Em particular, é de se destacar que: (i) Superior Tribunal de Justiça: permite pesquisa por inteiro teor. Informa ser "indiferente a digitação de palavras com letras maiúsculas, minúsculas ou acentuadas. O sistema também não distingue o 'c' do 'ç'." Expressão utilizada: "dépecage". Mecanismo de busca: <http://www.stj. jus.br/SCON/>; (ii) Tribunal de Justiça do Estado de São Paulo: permite pesquisa por inteiro teor. Não se encontrou informações sobre o uso de acentos. Assim, pesquisaram-se separadamente os termos: "dépeçage" e "D?pe?age". Mecanismo de busca: <https:// esaj.tjsp.jus.br/cjsg/consultaCompleta.do>; (iii) Tribunal de Justiça do Estado do Rio de Janeiro: informa o mecanismo ser indiferente 
Os resultados da pesquisa indicaram, entretanto, ausência de casos. Teriam os tribunais alterado o entendimento sobre a possibilidade de aplicação do dépeçage?

Desde já, a insuficiência deve ser mitigada e compreendida. Primeiramente, porque, como explicado, existem inúmeras variações do termo. A pesquisa se concentrou em uma delas com variantes fonéticas nos acentos. Em segundo lugar, a carência de resultados não significa necessariamente que o dépeçage não tenha sido utilizado. Pode ter sido plenamente empregado sem que o(s) julgador(es) tenha(m) aludido ao termo. Além disso, como ponto fundamental deste artigo, as variações semânticas e de abrangência do instituto relativizam ainda mais o resultado da pesquisa, como se propõe a partir da próxima seção.

\section{A problemática conceitual}

A partir desta seção será apresentada a doutrina comparada do dépeçage. Buscou-se diversidade de concepções nas raízes continentais e anglo-saxã. A partir delas, traz-se seu diálogo com a doutrina brasileira. Jus-

o uso de acentos, letras maiúsculas ou minúsculas. Entende-se que o mecanismo de busca é apenas indexado na ementa. Mecanismo de busca: <http://www.tjri.jus.br/scripts/weblink.mgw?MGWLP $\mathrm{N}=$ CONSULTA\&LAB $=$ JUR $x$ WEB\&PGM $=$ WEBJRP101 $\mathrm{xPRO}$ D\&PORTAL $=1 \&$ ROTINA $=$ WEBJRP102xPROD\&FLAGCON $\mathrm{TA}=0>$; (iv) Tribunal de Justiça do Estado de Minas Gerais: permite pesquisa inteiro teor. Não se encontraram informações sobre o uso de acentos. Assim, pesquisaram-se separadamente os termos: “dépeçage" e "D\$pe\$age". Mecanismo de busca: <http://www5. tjmg.jus.br/jurisprudencia/formEspelhoAcordao.do>; (iv) Tribunal de Justiça do Rio Grande do Sul: permite pesquisa inteiro teor. Não se encontraram informações sobre o uso de acentos. Portanto, pesquisaram-se separadamente os termos: "dépeçage" e "D\$pe\$age". No primeiro caso, a pesquisa resultou em seis (6) decisões. Porém, todas elas utilizam o termo de forma não técnica, sendo base comum das decisões a seguinte expressão "[...] um verdadeiro dépeçage de argumentos ventilados [...]”. Foram, consequentemente, descartados na análise. Mecanismo de busca: < http://www.tjrs.jus.br/ site/jurisprudencia/pesquisa_jurisprudencia/>; (v) Tribunal de Justiça do Paraná: permite pesquisa por inteiro teor. Não se encontraram informações sobre o uso de acentos. Assim, pesquisaram-se separadamente os termos: "dépeçage", "dépecage" e "D\$pe\$age". Mecanismo de busca: <https://portal.tjpr.jus.br/jurisprudencia/>; (vi) Tribunal de Justiça do Distrito Federal e Territórios: permite pesquisa por inteiro teor. Não se encontraram informações sobre o uso de acentos. Assim, pesquisaram-se separadamente os termos: "dépeçage" e "D\$pe\$age". Apenas um acórdão encontrado, em matéria criminal, pelo uso da máscara "\$”, mas sem relação com o objeto deste artigo. Mecanismo de busca: <http://pesquisajuris. tjdft.jus.br/IndexadorAcordaos-web/sistj?visaoId=tjdf.sistj.acordaoeletronico.buscaindexada.apresentacao.VisaoBuscaAcordao $>$. tificativas específicas sobre a escolha de determinados autores igualmente são feitas. Como em qualquer trabalho comparativo, a designação de países e autores implica a exclusão de outros, reconhecendo-se limites ao esforço investigatório.

\subsection{Doutrina Francesa e Alemã}

Com etimologia francesa, tomou-se como marco inicial a doutrina do dépeçage naquele direito. No clássico de Batiffol, o instituto é tratado na seção dedicada ao "domínio da regra da autonomia", sob o rótulo de morcellement du contrat. Segundo o autor, nem todas as questões relativas a um contrato seriam regidas pela regra de autonomia. Já seria de conhecimento que, pelo menos nos países de tradição continental, a capacidade seria regida pela lei pessoal (loi personelle), a forma do contrato pela lei do local de conclusão e os contratos sobre direitos reais pela lex rei sitae. Sinaliza o autor certa tendência, à época, de se definir como despedaçamento autêntico (véritable morcellement) a regência do contrato pelo (i) direito derivado do acordo das partes e (ii) pelo direito da execução dessas obrigações. Entretanto, e autor condena essa tendência. Cita a existência de uma unidade psicológica e econômica no contrato. Refuta a análise alemã, de um conglomerado de obrigações submetidos a direitos próprios, malgrada a autoridade de Savigny na matéria. Conclui que o instituto requereria inúmeros esclarecimentos para ser aplicado. ${ }^{6}$

Parte da doutrina francesa contemporânea reproduz a crítica de Batiffol, mas indica disposição para acolher mudanças. Audit, por exemplo, na reprodução da crítica, relembra que as regras clássicas de conflito assegurariam implicitamente ao que se denomina na França o "cumprimento do conjunto legislativo". Transposto para o conflito de normas, a ideia subjacente é a de que as regras aplicáveis a uma situação jurídica formem um conjunto coerente. Nesse sentido, uma e apenas uma lei deveria ser aplicada a uma situação, sob pena de se introduzir um desequilíbrio entre as partes. Regras de conflito, referidas pelo autor como muito específicas, poderiam se traduzir em um dépeçage de situações jurídicas gerador de incoerências. Não obstante, aponta que à medida que o direito de conflito francês passa a incorporar cada vez mais fontes do direito convencional (ex. Convenções de

6 BATTIFOL, Henri. Traité élémentaire de droit international privé. Paris: Librairie Générale de Droit et de Jurisprudence, 1949. p. 612-613. 
Haia e Direito Comunitário). Assim, em dinâmica similar a outros países europeus, podem se notar progressos e recuos. Progressos, no sentido de haver "filtragem" ou afinamento de regras com base em matérias muito específicas. Paradoxalmente, ocorreria uma atomização das questões em detrimento da coesão do conjunto, dogma caro à doutrina francesa ${ }^{7}$. Em obra mais recente, Audit reconhece, entretanto, que o dépeçage se justificaria em algumas situações. Por exemplo, em contratos complexos, formados por partes heterogêneas. Aduz o autor que a evolução contratual é insensível entre um contrato único, que comporta partes intelectualmente separáveis, ou um conjunto de contratos unidos por um vínculo estreito ${ }^{8}$.

Já Watt, ao discorrer sobre conflito de leis, sob a perspectiva de uma racionalidade econômica, constata situações de fracionamento, adicionando as variações terminológicas bundling e paquets indépeçables como antônimos do dépeçage $e^{9}$ A adição não representa uma posição necessariamente desfavorável ao instituto. Pelo contrário, a autora identifica situações favoráveis e desfavoráveis ao fracionamento em diversas áreas, extrapolando a discussão meramente do campo contratual (ex. arbitragem, mercado de capitais, falência e direito societário). ${ }^{10}$

Se se pode depreender vários elementos da análise do dépeçage na doutrina francesa, o mesmo pode ser feito por meio da doutrina alemã. Ao nos concentramos no clássico savignyano, A Treatise on the Conflict of Law, é curioso notar que o termo dépeçage não aparece destacado em seu índice. Tampouco é encontrado literalmente ao longo das seções dedicada aos direitos das obrigações. Não obstante, a ideia de se fracionar o direito em uma relação obrigacional multiconectada pode ser observada em determinadas passagens. ${ }^{11}$

Para que melhor se compreenda, Savigny, como é amplamente discutido na literatura de direito interna-

7 AUDIT, Bernard. Le droit international privé a fin du XXe siècle: progrès ou recul. Revue International de Droit Compare, v. 50, n. 2, p. 421-422; 447-448, 1998. Veja-se também que Audit e D'Avout fazem referência às variações terminológicas dépeçage e décomposition, admitindo a possibilidade de sua utilização.

8 AUDIT, Bernard; D'AVOUT, Louis. Droit internacional privé. 7. ed. Paris: Economica, 2013. p. 811-812.

9 WATT, Horatia Muir. Aspect économiques du droit international privé. Leiden: M. Nijhoff, 2005. p. 74-242.

10 WATT, Horatia Muir. Aspect Économiques du Droit International Privé. Leiden: M. Nijhoff, 2005. p. 74-75; 91-93; 135-137.

11 SAVIGNY, Friedrich Carl Von. A treatise on the conflict of laws and the limits of their operation in respect of place and time. London: Stevens and Sons, 1869. Seções XXVI-XXXI. cional privado, propõe como base para a solução de conflitos a regência da obrigação pela localização de sua verdadeira sede (true seat). A partir daí, já adverte sobre um dos problemas do direito obrigacional denominado reciprocidade. Quer dizer que, em obrigações mútuas, as duas partes da relação jurídica podem ser consideradas devedoras ao mesmo tempo. Onde estaria sua sede? Nesse caso, a regra de se aplicar a lei do devedor, uma das soluções possíveis, poderia ser separada de acordo com quem figura como devedor para cada uma das duas metades da obrigação. Trata-se da ideia contemporânea de bilateralidade obrigacional. Nela, Savigny sugere que a divisão pode resultar em direitos aplicáveis distintos. Deveria ser esse, inclusive, seu tratamento natural, uma vez que a combinação destas metades em apenas uma obrigação seria um artifício justificado pela conexão íntima entre cada metade. Corrobora sua visão com a prática ordinária romana de contratos de compra e venda. Duas estipulações eram utilizadas para se concluir o contrato ${ }^{12}$.

Em uma perspectiva de fracionamento mais amplo, Savigny aduz que não se pode admitir que todas as questões possíveis decorrentes da obrigação devam ser determinadas por somente uma lei regente ${ }^{13}$. O autor ilustra a situação com o então direito comum germânico em títulos de crédito. A capacidade das partes seria regida de acordo com a lei do domicílio da parte emissora do título, sendo o direito aplicável a sua substância questão distinta. Savigny além disso distingue questões de validade formal, regida pela locus regit actum, das condições materiais de validade das obrigações. A última seria regida, de acordo com as circunstâncias do caso, pela lei do local de cumprimento das obrigações, do local de celebração ou pelo domicílio do devedor ${ }^{14}$.

Observa-se, de tal modo, diferentes níveis do que se pode convencionar como fracionamento na análise savignyana. $\mathrm{O}$ primeiro, mais restrito, aplicável às obrigações em um mesmo contrato. $\mathrm{O}$ segundo, mais amplo,

12 SAVIGNY, Friedrich Carl Von. A treatise on the conflict of laws and the limits of their operation in respect of place and time. London: Stevens and Sons, 1869. p. 148-150.

13 "Although the seat of the obligation, and, at the same time, the local law that governs it, may upon the whole be determined with certainty by the rules here laid down, yet it must not be asserted that all possible questions of law occasioned by na obligation must be determined only by this local law." SAVIGNY, Friedrich Carl Von. A treatise on the conflict of laws and the limits of their operation in respect of place and time. London: Stevens and Sons, 1869. p. 177

14 SAVIGNY, Friedrich Carl Von. A treatise on the conflict of laws and the limits of their operation in respect of place and time. London: Stevens and Sons, 1869. p. 199. 
aplicável a questões separáveis como forma, substância e capacidade das partes em uma relação obrigacional, embora o autor não aluda expressamente ao termo.

Se até o momento, o artigo incursionou, como ponto de partida, na análise doutrinária na tradição continental, salutar verificar seu tratamento na raiz anglo-saxã. É o dépeçage pesquisado no contexto do conflito de leis, por exemplo, na doutrina norte-americana?

\subsection{Doutrina Norte-Americana}

Uma primeira observação a ser feita na pesquisa da doutrina norte-americana é o peculiar contexto do estudo de conflito de leis naquele país. Grande parte dos exemplos encontrados tem relação com conflitos privados intraestatais e não (privados) interestatais. A razão é que os Estados da federação norte-americana possuem autonomia para definir seus sistemas civis e processuais, embora com uniformizações ocorridas entre algumas de suas unidades. Assim, ocorrem conflitos dentro de uma mesma soberania em matérias que algumas tradições, como a brasileira, não se deparam. Não obstante, casos internacionais também são analisados à luz das mesmas regras do conflito de leis ou conflict of laws.

Reese, em artigo seminal, apontava o dépeçage como fenômeno comum e definia três versões possíveis. A primeira, mais ampla, cobriria todas as situações nas quais as normas de diferentes Estados são aplicadas para reger diferentes questões no mesmo caso. Estariam cobertos por sua definição casos, até mesmo, em que se fraciona o direito aplicável quanto às questões procedimentais e ao direito substantivo. Uma segunda perspectiva restringiria o alcance do instituto à aplicação das normas de diferentes Estados para questões substantivas no mesmo caso. A terceira definição, a mais restritiva, emergiria como uma solução pragmática. Confina-se às situações de fracionamento nas quais se chega a um resultado pela aplicação das normas de Estados distintos, que não poderia ser obtido pela aplicação exclusiva das normas de apenas um destes Estados ${ }^{15}$.

Juenger, tendo desenvolvido grande parte de sua docência nos Estados Unidos, e passados mais de um século da obra seminal de seu conterrâneo Savigny, confirma o quão problemático ainda restava uma teo-

15 REESE, Willis L. M. Dépeçage: a common phenomenon in choice of law. Columbia Law Review, n. 73, 1973. p. 58. ria consistente sobre o dépeçage. $\mathrm{O}$ autor chega mesmo a classificar como esotérico certos termos encontrados no conflito de leis, referindo-se, entre outros, ao dépeçage. Mesmo se escolhendo um determinado sistema jurídico, haveria amplas diferenças de opinião sobre seu significado, escopo e validade sob cada terminologia ${ }^{16}$. Avançando em sua crítica, Juenger localiza como uma das origens do problema conceitual a amplitude das categorias de Savigny. Uma análise mais refinada requereria a consideração se todos os aspectos de uma transação deveriam ser regidos pela mesma lei. Como parte da contribuição intelectual, oferece o autor a ideia do aparecimento de um espectro de dépeçage (spectre of dépeçage). Ele surgiria quando se admite que diferentes questões de um caso possam ser controladas por distintas leis; isto é, a confluência de regras decisórias de diferentes sistemas legais resultando em soluções compostas por diferentes elementos (composite solutions) $)^{17}$. Aponta, por fim, que acadêmicos dificilmente concordariam em quão finas devem ser as fatias das categorias no conflito de leis para efeitos de dépeçage, assim como na recombinação dessas fatias. O melhor que se poderia dizer sobre o instituto é que ele encoraja seletividade de resultados ${ }^{18}$.

Symeonides, em artigo mais recente, faz uma análise quantitativa e qualitativa do dépeçage. Quantitativamente, embora autores e cortes tomem o dépeçage como fenômeno comum e de ampla aplicação na realidade norte-americana, o instituto estaria mais presente nos exames da faculdade de direito do que na prática. Cinquenta anos após o paradigmático caso Babcock ${ }^{19}$, apenas 291 casos teriam sido identificados em uma pesquisa eletrônica. Qualitativamente, Symeonides justifica o baixo número de casos pelo simples fato de que nem todo caso multiconectado envolve mais que uma questão de escolha de lei aplicável. E mesmo casos que envolvessem várias questões não são necessariamente resolvidos pela aplicação de leis de diferentes Estado ${ }^{20}$.

Explana ainda Symeonides que houve uma transi-

16 JUENGER, Friedrich K. General course on private international law. Haia: Hague Academy of International Law Courses, 1983. p. 134. 17 JUENGER, Friedrich K. General course on private international law. Haia: Hague Academy of International Law Courses, 1983. p. 196. 18 JUENGER, Friedrich K. General course on private international law. Haia: Hague Academy of International Law Courses, 1983. p. 187. 19 Caso paradigmático para o estudo do conflito de leis nos Estados Unidos, embora o autor reconheça que não se trate de um caso de dépeçage, tal qual pelo autor definido.

20 SYMEONIDES, Symeon C. Issue-by-issue analysis and dépeçage in choice of law: cause and effect. The University of Toledo Law Review, n. 45, p. 13, 2013. 
ção de modelos no direito norte-americano. Em um primeiro momento, representado pelas regras do First Restatement ${ }^{21}$, existiria excessiva amplitude nas categorias para efeito de conflito de leis. Por exemplo, no que tange contratos, o local da celebração regeria capacidade, necessidade de consenso ou "consideração", fraude, ilegalidade e outras fontes de invalidade. O autor aponta a falta de flexibilidade daquele modelo levando a escolha de leis por atacado pelas cortes ${ }^{22}$. Essa abrasadora amplitude seria inclusive uma das razões para a tão conhecida Revolução Norte-Americana no conflito de leis, geralmente associada ao caso Babcock. Em um segundo momento, as cortes norte-americanas teriam evoluído para um modelo de escolha no varejo, utilizando uma análise de questão-por-questão (issue-by-issue). O Second Restatement, assim, reforçaria o tratamento por questões particulares e isso seria um dos poucos pontos nos quais haveria consenso nos Estados Unidos; isto é, uma análise mais restrita, por questões. Exemplifica o autor que duas unidades da federação teriam adotado, inclusive, esta orientação: Louisiana e Oregon ${ }^{23}$. Nelas, em conflitos contratuais, as questões de forma, capacidade e consenso são tratadas por regras de conflito distintas - modelo próximo ao sistema brasileiro, previsto na LINDB, como já mencionado.

Já quanto a uma definição do instituto, Symeonides propõe que o dépeçage é a aplicação de leis substantiva de mais de um Estado para diferentes questões na mesma causa de pedir (cause of action). Não seria doutrina, teoria, abordagem, princípio, regra, técnica, processo, nem mesmo objetivo da escolha de leis; é, simplesmente, o potencial e ocasional resultado da análise de questão-por-questão. Ocorreria dépeçage somente quando uma corte aplica o direito material de diferentes Estados a diferentes questões na mesma causa de pedir. Oferece igualmente contraexemplos. Quando uma corte aplica seu próprio

21 Embora pouco estudados no Brasil, os Restatements são produzidos pelo American Law Institute (ALI), organização privada e independente que agrega juízes, docentes e advogados com o intuito de aprimoramento e orientação interpretativa do common law norteamericano. Não há congênere no Brasil. Em nosso sistema, entendo que as Jornadas de Direito, sob a égide do Conselho da Justiça Federal, com a produção de enunciados não vinculativos, aproximam-se da dinâmica citada.

22 SYMEONIDES, Symeon C. Issue-by-issue analysis and dépeçage in choice of law: cause and effect. The University of Toledo Law Review, n. 45, p. 1-2, 2013.

23 SYMEONIDES, Symeon C. Issue-by-issue analysis and dépeçage in choice of law: cause and effect. The University of Toledo Law Review, n. 45, p. 4-5, 2013. direito processual (lei do foro) e um direito alheio à questão substantiva de uma obrigação, não haveria dépeçage. Igualmente, se em um mesmo caso existem duas causas de pedir, uma relativa ao contrato, com aplicação da lei do Estado A, e outra relativa a responsabilidade extracontratual, com a aplicação da lei do Estado B, não se estaria diante, propriamente, do dépeçage ${ }^{24}$.

Resumidamente, de forma similar à doutrina francesa e alemã, observam-se variações quanto à abrangência e recepção do dépeçage na doutrina norte-americana selecionada. Juenger, entretanto, parece representar uma posição intermediária, ao se concentrar menos em uma definição e mais na observação de um espectro de dépeçage. As múltiplas formas de fatiamento dos casos multiconectados, que opõe doutrinadores, conduz ao respectivo espectro. Ademais, entre os doutrinadores perfilados até o momento, Symeonides é o único a deslocar a análise do dépeçage para conceitos próprios da teoria processual (causa de pedir).

Feitas essas considerações da doutrina comparada, avança-se neste artigo para a doutrina brasileira. Repete-se a divergência conceitual? Em qual orientação ou forma de sistematização se pauta nossa doutrina?

\subsection{Doutrina Doméstica}

Similarmente às seções anteriores, procurou-se analisar parte da doutrina seminal e contemporânea do dépeçage. Nesse momento, porém, pela ótica de doutrinadores nacionais. Como esperado, observa-se interpolação intelectual entre autores nacionais e estrangeiros, principalmente de tradição continental.

Oscar Tenório discorrendo sobre o direito das obrigações e a autonomia da vontade, admite noções do que alguns considerariam uma discussão sobre fracionamento, em seu sentido mais amplo. Aduz que a liberdade convencional é mitigada por noções de leis imperativas. Em matéria de contratos, questões de capacidade e licitude do objeto lícito estariam disciplinadas por leis dessa natureza. E questiona, sem se utilizar do termo dépeçage ou qualquer terminologia próxima, como saber qual a norma imperativa aplicável ${ }^{25}$. Em breve

24 SYMEONIDES, Symeon C. Issue-by-issue analysis and dépeçage in choice of law: cause and effect. The University of Toledo Law Review, n. 45, p. 9, 2013.

25 TENÓRIO, Oscar. Direito internacional privado. 11. ed. Rio de Janeiro: F. Bastos, 1976. p. 174. 
passagem, o autor levanta, ademais, o questionamento acerca do que se poderia convencionar como um fracionamento mais restrito. Explica que, nesse caso, "a preocupação está no estabelecimento da lei única para as obrigações", reconhecendo divergências no plano internacional. A ideia encontraria amparo no já exposto na obra de Savigny. Nela, segundo o autor, aplicar-se-ia, às obrigações de cada parte, seu próprio direito, i e., para cada uma das obrigacôes sua própria lex loci solutionis. A técnica é mencionada como método - sem o uso da expressão dépeçage - e classificada como incômoda, mas que conduziria a resultados práticos e corresponderia a olhar "as coisas como elas são" ${ }^{\prime 26}$.

Valladão, novamente versando sobre autonomia da vontade na escolha da lei aplicável, e igualmente sem mencionar o termo dépeçage, admite a possibilidade de que a referência à lex fori ou à lei estrangeira possa ser feita total ou parcialmente "para cadaparte do contrato"27. Menciona, ademais, curioso estudo em que o fracionamento poderia se estabelecer até mesmo em matérias procedimentais nas quais, tradicionalmente, toma-se como dado a aplicação de somente uma lei - a do foro (ordinatorium litis). A hipótese, embora não detalhada, seria encontrada em estudo do Professor Szászy em que se advoga não mais a aplicação integral da ordinatorium litis mas o critério das matérias mais ligadas ao processo (que normalmente coincidem, mas não necessariamente $\mathrm{o}$ são). Nesse caso, aplicar-se-ia a norma processual da lei própria do contrato ou da lex civilis causae ${ }^{28}$.

Já Dolinger, ao incursionar por seis séculos na obra de Bártolo, utiliza expressões como bifurcação e cisão para relembrar que o clássico autor italiano já havia cindido o direito aplicável aos contratos internacionais. Bártolo teria se utilizado de em um critério temporal para aplicar regras de conflito distintas. O momento de assinatura do contrato faz com que questões relativas à sua validade, substância, interpretação e efeitos fossem regidas pela lei de feitura do contrato. Já o momento das consequências finais do contrato faz com que questões como negligência, inadimplemento e forma de execução fossem regidos pela lei de local do cumprimento (se fixado pelas

26 TENÓRIO, Oscar. Direito internacional privado. 11. ed. Rio de Janeiro: F. Bastos, 1976. p. 176 e nota de rodapé 14.

27 VALLADÃO, Haroldo. Direito internacional privado: em base histórica e comparativa, positiva e doutrinária, especialmente dos estados americanos. 5. ed. Rio de Janeiro: F. Bastos, 1980. p. 369.

28 VALLADÃO, Haroldo. Direito internacional privado: em base histórica e comparativa, positiva e doutrinária, especialmente dos estados americanos. 5. ed. Rio de Janeiro: F. Bastos, 1980. p. 378. partes) ou pela lex fori (se não fixado) ${ }^{29}$. Ademais, em concisa passagem, acena o autor que a distinção entre a lei que rege a capacidade e a lei que rege o contrato estaria contida em uma teoria do dépeçage. Nela se aceitaria o desmembramento dos vários aspectos de uma relação jurídica transnacional, embora o autor também não a detalhe ${ }^{30}$.

Contemporaneamente, autores oscilam entre versões mais amplas e mais restritas do instituto. Nadia de Araujo, aludindo à complexidade dos contratos internacionais e aos ensinamentos de Savigny, define o instituto como "mecanismo pelo qual um contrato ou uma instituição é dividida em diferentes partes, que serão, cada uma delas, submetidas a leis diferentes". Explica sua ocorrência em dois níveis: (i) derivado do próprio sistema de direito internacional privado que, por exemplo, faz com que a substância de um contrato seja regida por uma lei e a capacidade, forma e execução por outra; e (ii) derivado e resultado do desdobramento da autonomia das partes, em função da faculdade delas determinarem mais de uma lei aplicável ao contrato. Reforça sua posição com a doutrina de Maria Helena Diniz e Grandino Rodas que, respectivamente, teriam se referido ao dépeçage como (i) "método analítico mais profundo de todos os elementos de conexão" e (ii) "opção realista pela aceitação de que [a relação de contratos internacionais] seja regida por mais de um sistema jurídico, aplicando-se o morcellement, com a consequente aplicação de vários direitos" ${ }^{\prime 1}$.

Basso, por sua vez, no que toca ao dépeçage decorrente da autonomia da vontade das partes, define-o como a "divisão do contrato de forma que cada sessão ou segmento seja submetido a sistemas nacionais diversos". Condiciona-o, entretanto, à ausência de resultados contraditórios quando da escolha de diversos direitos aplicáveis.

29 DOLINGER, Jacob. Direito internacional privado (parte especial): direito civil internacional: contratos e obrigações no direito internacional privado. Rio de Janeiro: Renovar, 2007. p. 235-237; p. 486-489. 30 DOLINGER, Jacob. Direito internacional privado (parte especial): direito civil internacional: contratos e obrigações no direito internacional privado. Rio de Janeiro: Renovar, 2007. p. 446.

31 ARAUJO, Nadia de. A autonomia da vontade nos contratos internacionais: situação atual no Brasil e no Mercosul. Revista do Ministério Público, n. 6, p. 156-157, 1997. ARAUJO, Nadia de. Contratos internacionais e a jurisprudência brasileira: lei aplicável, ordem pública e cláusula de eleição de foro. in: RODAS, João Grandino (Org.). Contratos . 3. ed. São Paulo: Revista dos Tribunais, 2002. p. 207-208. De forma similar, na edição mas recente: ARAUJO, Nadia de. Direito internacional privado: teoria e prática brasileira. Porto Alegre: Revolução eBook, 2016. Item 19.3 com notas de rodapé. 
Conclui, assim, não ser de fácil aplicação, compartilhando a visão de que o contrato deve ser regido por uma única lei. Abre, porém, exceção à hipótese de um grande contrato que possa ser decomposto em outros separáveis e independentes ${ }^{32}$.

Como sinopse, mais uma vez se observam versões abertas e contidas do instituto. É de se notar a possível identificação do dépeçage, por Dolinger, já na longínqua doutrina de Bártolo, por meio das expressões bifurcação e cisão. Chama à atenção, igualmente, a possibilidade do dépeçage em questões de direito processual em tese que, embora mencionada por Valladão, encontra-se pouco desenvolvida. Além disso, é importante notar as visões contemporâneas que, pragmaticamente, apontam como fonte do instituto o próprio sistema de direito internacional privado ou a autonomia das partes, conforme Nadia de Araujo.

A próxima seção evolui para: (i) agrupar argumentos lógicos encontrados nas doutrinas expostas; (ii) e reconhecer diferentes níveis de dépeçage que, em algumas situações, confundem-se com outros conceitos jurídicos. Com isso, permitir-se-á que se desmistifique e se relativize o resultado da pesquisa engendrada.

\section{Agrupando os entendimentos Sobre 0 DÉPEÇAGE}

Do exposto das fontes doutrinárias comparadas e nacionais, é possível agrupar entendimentos comuns e demarcar diferenças na análise do dépeçage. Decerto, outros agrupamentos poderiam ser feitos. A análise poderia se desenrolar em torno das fontes do dépeçage (volitiva ou sistêmica); ainda, pelo desenvolvimento dos argumentos consequencialistas, revelando-se visões sobre os potenciais benefícios e custos do dépeçage $e^{33}$. O foco, entretanto, é o contraponto entre variações conceituais e ausência da observação jurisprudencial.

Como visto, as distintas narrativas doutrinárias giraram em torno de um padrão de sintaxe relativamente

32 BASSO, Maristela. A autonomia da vontade nos contratos internacionais de comércio. In: BAPTISTA, Luiz Olavo; HUCK, Hermes Marcelo; CASELLA, Paulo Borba (Org.). Direito e comércio internacional: tendências e perspectivas. São Paulo: LTR, 1994. p. 53.

33 Notadamente, quanto à fonte, Batiffol e, no caso brasileiro Tenório e Nadia de Araujo. Já quanto ao consequencialismo, vejamse o já referido em Batiffol, Audit e Juenger. No caso brasileiro, Tenório e Basso, sendo ponto comum uma visão pouco otimista quanto ao dépeçage. determinável. Em linguagem formal, a sintaxe se concentrava em determinados núcleos nominais complementados por adjuntos. Especificamente, observou-se predominância do núcleo "questão" e do adjunto - ou locução - "do contrato/contratual”.

A figura seguinte representa o sugerido, sendo que núcleos e adjuntos possuem mais de uma combinação.

Figura 1 - Núcleos e Adjuntos do Dépeçage

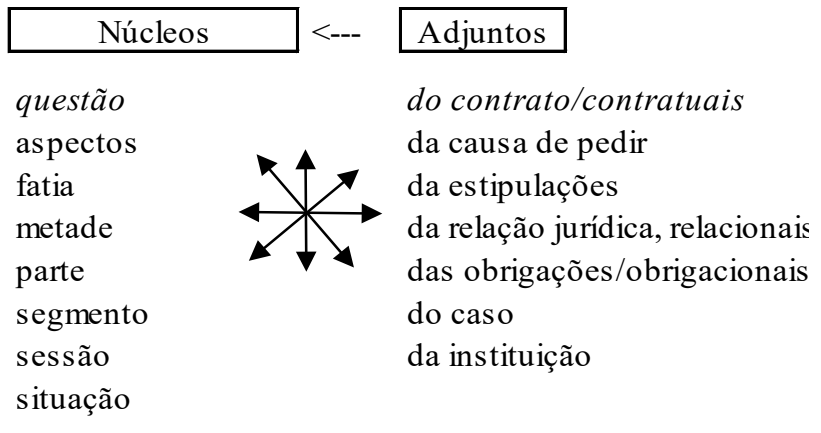

Fonte:

A diversidade de definições doutrinárias, entretanto, não pode ser caracterizada precipuamente pelas possíveis combinações entre núcleos e adjuntos. Sugiro que, muito mais, em função do que cada autor considera como uma questão, uma situação, uma metade, uma parte, uma fatia etc. do contrato; em termos sintáticos, o tipo de aposto que esclareceria cada núcleo.

Nas concepções mais restritas que expressamente mencionam o termo dépeçage - admitidas em Batiffol, Audit, Reese e Symeonides, e, na doutrina nacional, em Nadia de Araujo e Basso -, o que se entende por questão, ou por seus núcleos equivalentes, orbita em torno da substância ou do fundo contratual ${ }^{34}$. Nas acepções mais amplas que manifestamente usaram o termo dépeçage - Batiffol, Reese e Symeonides, e, na doutrina pátria, Dolinger e Nadia de Araujo -, o termo é utilizado com outro propósito. Isto é, quando a capacidade dos contratantes, a forma do contrato e a sua substância são regidos por leis de distintos sistemas ocorreria o dépeçage.

Por isso, bem empregada por Juenger a expressão espectro de dépeçage. Ao invés de se concentrar em uma definição consistente, reconhece o autor variações, o que corresponde ao que sugerimos ser mutações no conteúdo de cada núcleo.

34 Se não levarmos em conta a expressa menção ao termo, mas apenas a ideia do dépeçage que pode ser subsumida de forma mais restrita, adicionaríamos: Savigny, na doutrina comparada, e Tenório, Valladão e Dolinger, na nacional. 
Ademais, no limite, as versões demasiadamente dilatadas como ilustração do dépeçage encontram menor guarida doutrinária. Por exemplo, apenas Reese, em sua versão amplíssima do conceito, sugere que quando, em um caso, a lei processual (lex forr) e a lei da substância do contrato não coincidem, tem-se uma espécie de dépeçage. E são também essas situações que atraem manifestações diretamente opostas do que não é dépeçage, como sugerido por Symeonides. Este autor, inclusive, ao contrário de todos, é o único que desloca o dépeçage para uma questão processual: a causa de pedir. Entretanto, não resolve o dilema do conceito - aliás parece não ser esse o seu propósito. Simplesmente, entendemos que a discussão é transposta para mais um tipo de núcleo, pertencente ao direito processual.

Procuremos ilustrar as ideias acima expostas. Como ponto de partida, tomemos um contrato celebrado presencialmente entre duas partes nas seguintes circunstâncias: (i) a parte "P1" possui domicílio no Estado "E1", a outra "P2", no Estado "E2"; (ii) o contrato, celebrado presencialmente entre "P1" e "P2", em "E2", estabelecia que, quanto ao direito aplicável, aplicar-se-ia o direito de "E2", para o inadimplemento do contrato, e o direito de "E1", em relação a sua extinção; e (iii) em um eventual litígio, a controvérsia foi trazida à apreciação da jurisdição "E1" em função, por exemplo, da escolha de foro entre as partes.

\section{Espectros do dépeçage surgem ao se considerar que:}

Na versão mais restrita do espectro: assumindo-se uma regra de conflito pró-autonomia da vontade para contratos internacionais na jurisdição "E1", o contrato seria regido, em sua substância, por pelo menos dois corpos de normas: a do Estado "E2" (para inadimplemento) e a do Estado "E1" (para sua extinção) ${ }^{35}$;

Na versão mais ampla do espectro: assumindo-se uma regra de conflito, na jurisdição "E1", remetendo a capacidade do contratante à lei de seu domicílio, a capacidade de "P2" seria regida pela lei do Estado "E2", ao passo que questões substantivas do contrato seriam regidas, potencialmente, por outro corpo de normas: "E1" para, por exemplo, a extinção do contrato. Também não parece improvável admitir que, nessa mesma lógica, devido

35 O exemplo se baseia em regras de origem estatal "E1" e "E2", mas é de se questionar se o mesmo raciocínio seria aplicável caso a menção do direito aplicável tivesse sido feita a regras uniformes ou costumeiras não-estatal (ex. lex mercatoria, INCOTERMS, princípios da UNIDROIT etc.). ao fato da capacidade do contratante "P1" se reger pela lei de "E1"e a do contratante "P2" se reger pela lei de "E2" haveria dépeçage. O problema, naturalmente, é que estaríamos diante do fracionamento em praticamente todo contrato em que qualquer elemento de conexão remeta à aplicação potencial de mais de um direito. $\mathrm{O}$ dépeçage passa a se confundir com as inúmeras possibilidades ou a própria disciplina do conflito de leis;

No limite da amplitude do espectro: ao processo submetido à jurisdição "E1", aplicar-se-á o direito processual do "E1" (lex for $)$, ao passo que a capacidade da parte "P2" e o inadimplemento do contrato terão a regência orientadas pelas normas de "E2". Como já proposto, este limite avança ainda mais a hipótese do dépeçage. É pertinente se questionar, contudo, se se chega a alterar as unidades de análise ou, em última instância, hipóteses de incidência de normas de distintas naturezas. Nos dois primeiros espectros estamos diante de questões resolvíveis, após a incidência das normas conflitivas, por normas pertencentes ao que denominamos direito civil. No último caso, alcançaríamos normas concernentes aos ramos do direito processual civil e civil.

Embora factível o exercício do espectro, deve-se admitir que as dificuldades não desaparecem por completo. Há mesmo um problema de definição recursiva ou tautologia. Em última análise, deve-se relembrar a problemática da "qualificação" ou "classificação" no direito internacional privado. Explica-se. Uma determinada ordem jurídica pode classificar como substância algo que é considerado como matéria processual em outra jurisdição. Apenas para que fiquemos em um exemplo, prescrição obrigacional é tema que envolve visões distintas sobre sua natureza - ora processual, ora material - a depender da jurisdição em foco. Igualmente, um sistema jurídico pode classificar como matéria de fundo do contrato a questão da capacidade das partes contratantes. Por isso, reforça-se uma visão de que mais do que uma definição, a ideia de Juenger de espectros de dépeçage, ainda que imperfeita, orienta-se para uma observação sobre distintos graus e amplitudes do termo. Ao mesmo tempo permite que se teçam críticas sobre a localização das faixas de cada espectro em relação a outros conceitos encontrados na matéria.

A partir destas considerações, pode-se entender como ilusória a ausência do dépeçage na pesquisa empreendida na jurisprudência brasileira. Se consideramos os espectros do dépeçage sugeridos para as versões mais 
amplas e no limite do termo, poderíamos concluir por sua existência em nosso modelo. Afinal, a versão mais ampla representa o que atualmente já são as disposições da LINDB para o direito aplicável à capacidade e substância. A crítica é que, nesse caso, dépeçage se entrelaçaria com as próprias possibilidades e dinâmica do conflito de leis. No limite do espectro, teríamos um nível de fracionamento envolvendo regra de direito civil e processual civil, também retrato de como funciona atualmente nosso sistema. Por fim, entendemos que a versão mais restrita do dépeçage, para ser reconhecida como parte de nosso sistema, muito dependeria da aceitabilidade da autonomia da vontade em matéria contratual internacional $^{36}$. É de se salientar, apenas, que regras específicas aplicáveis aos contratos cobertos pela CISG, brevemente notadas, possuem o condão de alterar entendimentos, merecendo pesquisa continuada.

\section{Considerações finais}

Ao iniciarmos essa pesquisa partimos de um paradoxo gerador de uma inquietação. A doutrina selecionada - comparada e nacional -, de um lado, fazia menção ao termo dépeçage como algo presente no conflito de leis envolvendo contratos internacionais. Por outro lado, a jurisprudência brasileira recente (2006-2015), quando pesquisada, não revelava o uso do termo.

A primeira reação poderia ser a de que não se utiliza o dépeçage no sistema de conflito de leis brasileiro. Concluímos, entretanto, o quão ilusório seria essa afirmação.

Do ponto de vista de uma metodologia de busca de jurisprudência, inúmeras variações do termo, e o mero fato de que cortes podem estar se orientando pela ideia de fracionamento sem expressamente aludir a uma expressão pré-determinada, mitigam a falta de resultados. Além disso, do ponto de vista da concepção do que seja dépeçage, variações de sua semântica e abrangência relativizam ainda mais o resultado da pesquisa.

Se uma pretensa precisão do dépeçage não foi contornável, reforçamos a sugestão de Juenger no sentido de se observarem espectros do dépeçage. Ao propormos o agrupamento de núcleos e seus respectivos adjuntos, podemos melhor identificar três desses espectros, em linha com o que, parcialmente, a doutrina sugeria: mais

36 Veja-se nota de rodapé 2. restrito, mais amplo e no limite da amplitude, com críticas a cada uma destas faixas do espectro.

O primeiro espectro representa um maior desafio de observação em casos práticos no Brasil, em função da aceitabilidade ou não da autonomia da vontade quanto ao direito aplicável, face à LINDB. As outras duas faixas de espectro, entretanto, correspondem atualmente ao modus operandi da LINDB sendo observadas, sem maiores esforço, no sistema brasileiro.

\section{REFERÊNCIAS BIBLIOGRÁficas}

ARAUJO, Nadia de. A autonomia da vontade nos contratos internacionais - situação atual no Brasil e no Mercosul. Revista do Ministério Público, n. 6, 1997.

ARAUJO, Nadia de. Contratos internacionais e a jurisprudência brasileira: lei aplicável, ordem pública e cláusula de eleição de foro. In: RODAS, João Grandino (Org.). Contratos internacionais. 3. ed. São Paulo: Revista dos Tribunais, 2002. p. 195-229.

ARAUJO, Nadia de. Direito internacional privado: teoria e prática. Rio de Janeiro: Renovar, 2004.

ARAUJO, Nadia de. Direito internacional privado: teoria e prática brasileira. Porto Alegre: Revolução eBook, 2016.

AUDIT, Bernard. Le droit international privé a fin du XXe siècle: progrès ou recul. Revue International de Droit Compare, v. 50, n. 2, 1998.

AUDIT, Bernard; D’AVOUT, Louis. Droit internacional Privé. 7. ed. Paris: Economica, 2013.

BASSO, Maristela. A autonomia da vontade nos contratos internacionais de comércio. In: BAPTISTA, Luiz Olavo; HUCK, Hermes Marcelo; CASELLA, Paulo Borba (Org.). Direito e comércio internacional: tendências e perspectivas. São Paulo: LTR, 1994.

BATTIFOL, Henri. Traité élémentaire de droit international privé. Paris: Librairie Générale de Droit et de Jurisprudence, 1949.

CONSELHO NACIONAL DE JUSTIÇA. Justiça em números 2015: ano-base 2014. Brasília: CNJ, 2015.

DOLINGER, Jacob. Direito internacional privado (parte especial): direito civil internacional: contratos e obrigações no direito internacional privado. Rio de Janeiro: Renovar, 2007. 
JUENGER, Friedrich K. General course on private international law. Haia: Hague Academy of International Law Courses, 1983.

PIGNAT'TA, Francisco Augusto. Comentários à Convenção de Viena de 1980: artigo 6. 2012. Disponível em: http:// www.cisg-brasil.net/doc/fpignatta-art6.pdf.

REESE, Willis L. M. Dépeçage: a common phenomenon in choice of law. Columbia Law Review, n. 73, 1973.

RODAS, Jõao Grandino. Elementos de Conexão do Direito internacional privado brasileiro relativamente às obrigações contratuais. In: RODAS, João Grandino (Org.). Contratos internacionais. 3. ed. São Paulo: Revista dos Tribunais, 2002. p. 19-65.

SAVIGNY, Friedrich Carl Von. A treatise on the conflict of laws and the limits of their operation in respect of place and time. London: Stevens and Sons, 1869.
SCHLECHTRIEM, Peter; SCHWENZER, Ingeborg. Comentários à Convenção da Nações Unidas sobre Contratos de compra e venda internacional de mercadorias: artigo 6. São Paulo: Revista dos Tribunais, 2014.

SYMEONIDES, Symeon C. Issue-by-issue analysis and dépeçage in choice of law: cause and effect. The University of Toledo Law Review, n. 45, 2013.

TENÓRIO, Oscar. Direito internacional privado. 11. ed. Rio de Janeiro: F. Bastos, 1976.

VALLADÃO, Haroldo. Direito internacional privado: em base histórica e comparativa, positiva e doutrinária, especialmente dos estados americanos. 5. ed. Rio de Janeiro: F. Bastos, 1980.

WATT, Horatia Muir. Aspect Économiques du droit international privé. Leiden: M. Nijhoff, 2005. 
Para publicar na Revista de Direito Internacional, acesse o endereço eletrônico www.rdi.uniceub.br ou www.brazilianjournal.org.

Observe as normas de publicação, para facilitar e agilizar o trabalho de edição. 